\title{
Behavior of Electrodeposited Fe/FeSi Composite in a Static Parallel Magnetic Field
}

\author{
Qiong Long ${ }^{1,2,3, *}$, Yunbo Zhong ${ }^{3}$, Yujiao $W u^{2,3}$, Yingfen Li ${ }^{2,3}$, Juan $L^{2,3}$ \\ ${ }^{1}$ Guizhou Key Laboratory for preparation of light metal materials, Guizhou Institute of Technology \\ Guiyang 550003, China \\ ${ }^{2}$ Guizhou collaborative innovation center of special function materials, Guiyang 550003, China \\ ${ }^{3}$ Shanghai Key Laboratory of Modern Metallurgy and Material Processing, Shanghai University, \\ Shanghai, 200072, China \\ *E-mail: qiong12030@163.com
}

doi: $10.20964 / 2019.10 .38$

Received: 7 June 2019 / Accepted: 6 August 2019 / Published: 30 August 2019

Fe-Si composite coatings were electrodeposited with $\mathrm{Fe}-30 \mathrm{wt} \% \mathrm{Si}$ or Si particles on low silicon steel strips under a static magnetic field, the direction of imposed magnetic field kept parallel to electric field. The effects of magnetic field on the co-deposition process of magnetic Fe-30wt\% Si particles and weak diamagnetic Si particles were investigated. With increasing the magnetic field flux (MFD), the hummocky structures were gradually transformed from the rod-like structures induced in a weak magnetic field. However, bean-like structures on the coating surface of Si particles became more obvious with the increase of MFD. The experimental results revealed that the magnetic property and conductivity of added particles had a great effect on the migration behavior and co-deposition of particles in magnetic fields.

Keywords: Magnetic field; Co-deposition; Fe-Si particle; MHD effect; Filed gradient force

\section{FULL TEXT}

(C) 2019 The Authors. Published by ESG (www.electrochemsci.org). This article is an open access article distributed under the terms and conditions of the Creative Commons Attribution license (http://creativecommons.org/licenses/by/4.0/). 